\title{
The Spectre of the Drunkard
}

The issue of drunkenness cast a long shadow over the Victorian period and effectively masked ideas about the social benefits or pleasures to be gained from alcohol consumption. Ideas about the drunkard fuelled political and moral debates about the extent of liquor controls in Britain and drunkenness was the bane of the drink trade; leading to political organisation and the formation of trade defence leagues later in the period. As ideas about the causes and extent of drunkenness changed, so too did the proposed solutions and in the last quarter of the nineteenth century, the parliamentary enquiries came thick and fast as the drink question topped political agendas.

This chapter provides an overview of the political responses to the issues of drunkenness in the Victorian period. The common enemy of both the state and the drink trade was the drunkard-a figure that emerged from public fears and moral concern about the drinking culture of the urban working classes which was constantly on public showspilling onto the streets of industrial cities and towns, threatening public order and obstructing social and moral progress. By the late nineteenth century, the drunkard was believed to dwell not only on city streets, prisons and workhouses but also in asylums and hospitals. Although thought to exist mainly among the labouring population, the drunkard did not respect other social boundaries and breached gender, region, age, religion and ethnicity. The drunkard was viewed as a social pest and a danger to civilised and progressive society but perhaps most notably, the drunkard posed a very real threat to the majority of moderate drinkers

(C) The Author(s) 2018

T. Hands, Drinking in Victorian and Edwardian Britain, https://doi.org/10.1007/978-3-319-92964-4_2 
because the political measures taken to thwart intemperance affected everyone. Towards the end of the century, as the grip of tighter licensing laws took hold, the drink trade made efforts to legitimise their existence as a vital and respectable part of British society.

\section{The Legislative Jigsaw}

The 1899 Report of the Royal Commission on Liquor Licensing Laws contained a summary of the various parliamentary commissions on alcohol held during the nineteenth century. ${ }^{1}$ The summary report was commissioned by Lord Peel (1829-1912) who chaired the enquiry for most of its duration from 1897 to 1899. David Fahey notes that Peel's appointment was mainly due to his reputation for impartiality but during the course of the enquiry, for some unknown reason, he underwent 'a drastic conversion to temperance principles.' 2 Peel's conversion split the committee who then produced two reports that differed over their recommendations for reducing the numbers of public houses and granting compensation for loss of licenses. By the end of the nineteenth century, the drink question must have seemed like a legislative jigsaw puzzle composed of a succession of ill-fitting political strategies. Peel perhaps regarded it as his task to make a decisive impact upon the confusion of liquor licensing and in order to do so, he enlisted the skills of Mr R. A. Smith, an archaeologist at the British Museum. Exactly why he chose an archaeologist for this job is unclear. However, Smith's task was to review the various parliamentary enquiries on alcohol sale, licensing and intemperance which spanned the course of the century.

Smith's survey began in 1817 with the Select committee on the State of Metropolitan Police and the Licensing of Victuallers and ended in 1888 with the Select Committee on Sunday Closing Acts. During that time, there were 28 parliamentary enquiries into the issues surrounding alcohol sale and consumption in England, Wales, Scotland and Northern Ireland. ${ }^{3}$ Each major enquiry was subjected to a meticulous analysis, which formed part of a concise overview of the political process relating to alcohol throughout most of the nineteenth century. The report showed that by the end of the century, intemperance remained a pressing political issue despite numerous enquiries and legislative attempts to control the drink trade and limit alcohol consumption. Yet Peel did not believe that this marked any kind of failure in the political process. On 
the contrary, he believed that Smith's report highlighted the important work done by parliamentary enquires

It is commonly asserted that such enquiries never result in anything. Anyone at all familiar with the liquor laws and their history, who will glance at these pages, will see how wide of the truth these assertions are; even from the point of view of those who regard immediate legislation as the only test, and forget the work done, sometimes constructive, sometimes beneficially destructive, in the formation and education of opinion. ${ }^{4}$

Peel had faith in the political process and the summary report was perhaps intended as a testament to the complexity and thoroughness of the parliamentary investigations into the issues that surrounded the sale and consumption of alcohol. From a historical perspective, Smith's report is not only useful in providing a concise chronological summary of the main parliamentary enquiries but also as a means of identifying and situating the issues that surrounded the drink question and the various solutions proposed over the course of the century (see Appendix for the full table of enquiries).

The report began in 1818 when it was felt that the major brewers held a monopoly of tied (brewery owned) public houses in England and Wales and as a consequence, the public were forced to buy poor quality, over-priced beer and spirits. The solution was The 1830 Beer Act which was intended to weaken the position of the major brewers, discourage spirit drinking and promote the sale and consumption of better quality beer. However, this was a tall order considering the tempting and plentiful supply of cheap beer and spirits available to the burgeoning working classes within industrial towns and cities. The failure of the Beer Act to tackle intemperance was a constant theme during The 1834 Select Committee on Intoxication Among the Labouring Classes. It was believed that working-class drunkenness was the result of ingrained and problematic drinking customs; this belief essentially placed excessive drinking as a central feature of working-class life. The Beer Act was thought to have exacerbated drunkenness because it led to the proliferation of pubs and cheaper drinks. Therefore, the solutions proposed by the 1834 Committee were to limit access to alcohol by reducing pub numbers, regulating licensing and promoting alternative drinks such as tea and coffee. These were fairly radical recommendations for the time as they ran counter to laissez-faire principles and the rights of 'free men' 
to drink whatever and whenever they chose. However, the recommendations were, in Peel's opinion at least, the result of a thorough investigation of the drink problem, which he believed some of the later committees had failed to achieve. The parliamentary committees of the 1850s and 1860s had to deal with different aspects of the drink question and if their investigations and recommendations appeared weak to Peel, it was perhaps because they were in a sense dealing with a new set of problems that came in the wake of The 1830 Beer Act.

By mid-century, it was no longer a case of blaming drunkenness on the customs of the working classes or on the practices of brewers. Instead, drunkenness was explicitly linked to increases in poverty, crime and disorder among the working classes. Industrialisation and urbanisation had created new drinking cultures, and the Beer Act was instrumental in this process. It was believed that since the 1830s, there were more pubs of poorer quality and more 'bad characters' drinking than ever before. ${ }^{5}$ The Beer Act had forged a distinction between beerhouses and pubs selling beer and spirits, which in turn fuelled competition to sell even more cheap spirits and beer to working-class populations. The solutions proposed were to tighten and simplify the licensing system and to also promote counter attractions for the working classes to steer them away from drunkenness and point them towards the sober pastimes offered by rational recreation.

The mid-century climate of moral improvement was evident in the 1850s and 1860s parliamentary commissions that examined the licensing system. By this time, the temperance movement was at its peak and drunkenness was encased within a moral framework but this was a framework still supported by laissez-faire ideology which favoured freedom of commerce. In effect, people had the absolute right to sell and consume alcohol but getting drunk was viewed as an individual moral failing. The type of alcohol consumed by the industrial working classes was also a cause of concern and spirit drinking in particular was singled out as a pernicious cause of intemperance. Therefore, one of the aims of The 1860 Wine and Refreshment Houses Act was to promote the sale and consumption of wine, which was not only less intoxicating than spirits but was also believed to promote more 'civilised' drinking habits.

However, by the 1870 s drunkenness among the urban working classes was thought to prevail and it was no longer just a moral failing or a cause of crime and poverty but it was also believed to cause physical and mental illness. ${ }^{6}$ With the weight of this added problem, the drink question 
sank beneath the buoyancy of laissez faire. At a political level there was a pressing need to reform the licensing system, rein in the power of the drink trade and 'rescue' the working classes from the moral and physical ravages of intemperance. As Harrison notes, The 1872 Licensing Act may have marked a minor victory for the temperance movement but it did not erase the issue of intemperance, which carried on regardless until the tighter licensing restrictions brought in during the First World War. ${ }^{7}$ However, the parliamentary enquiries after 1872 were no longer constrained to the same extent by laissez faire-the state had already taken its first major step towards tighter control of alcohol sale and consumption. The main question driving the parliamentary enquiries after 1872 was the extent to which those controls should impinge upon the rights to sell and consume alcohol.

By the time that Peel chaired the 1897 commission, there was a vast array of proposed reforms to the licensing system ranging across a spectrum of direct state control of the alcohol trade to stepping up local powers to control licensing. As James Nicholls notes, the sheer number of proposed schemes was staggering but it was indicative of the general push towards restricting the trade in alcohol. ${ }^{8}$ The drunkard had not exactly disappeared but was instead reimagined as the undesirable and often detestable product of a morally questionable profit-driven industry. Therefore, increasingly, the drink trade fell under the spotlight of public and political scrutiny for its culpability in creating the social problems associated with drunkenness. This was evident in another parliamentary enquiry held at the end of the century. In 1895 The Departmental Committee on Habitual Offenders (Scotland) dealt extensively with issues related to drunkenness in towns and cities across Scotland. Police statistics showed higher levels of drink-related crime in Scotland as compared to England and one of the committee's tasks was to investigate the causes of drink-related crime. There was the suggestion that policing tactics varied, and that in England, the lower number of arrests could be due to more lax procedures for dealing with drunkenness. ${ }^{9}$ However some witnesses pointed the finger of blame towards publicans who continued to supply alcohol to drunken people

There are some publicans-perhaps we can hardly say a majority or minority - who are very conscientious but there are others that are not so. There is no doubt that publicans know drunkards who go in and get drunk week after week. They are known to the police, to their neighbours, 
and to the publicans to be drunkards and yet they are supplied in these houses till they are drunk. ${ }^{10}$

Throughout that enquiry, Scottish publicans constantly came under scrutiny as a potential source of drink-related crime and public disorder. Scotland seemed to have a more widespread problem with drunkenness and the drink trade was held to account. It therefore became necessary for the trade to mount a defence against further political and legislative 'attacks' and promote its business as both vital and respectable. Above all it had to distance itself from the drunkard.

\section{The Problems of Promoting A 'Happiness Inducing Business'}

In the late Victorian period, Scottish alcohol producers and retailers formed local and national trade defence organisations. One of the ways to promote and protect business interests was through the publication of weekly or monthly trade journals. In Scotland three of the prominent trade journals were The Scottish Wine, Beer and Spirits Trades Review, The Victualing Trades Review and The National Guardian, all of which circulated from around the 1880s onwards. The main purpose of these journals was to harness interest and support in trade defence activities and to promote and advertise local and national businesses. The journals also reported on national drink issues such as parliamentary enquiries on alcohol, legislation and temperance campaigning. What really stands out from the journals is the absolute conviction that the drink trade was unfairly targeted because it was a legitimate and respectable business which served the public and generated substantial revenue for the nation. There was however no escaping the fact that it was a business that dealt in the somewhat controversial realm of intoxication. An article on 'why people drink' in The National Guardian in 1913 described the act of consuming alcohol as 'a happiness inducing business' and this in essence captures the way the drink trade aimed to be perceived both internally and externally. ${ }^{11}$

One of the themes that arose constantly within the journals was the allegedly 'ludicrous' and 'fanatical' standpoint of the temperance movement, particularly the teetotal faction. Articles that reported on temperance meetings or rallies did so with a mercilessly scathing and hostile 
tone. An article on the Scottish temperance societies in The National Guardian in 1904 launched an attack on the perceived failings of the temperance movement. After sixty years of campaigning, drunkenness prevailed and it was felt that the movement had achieved little more than to 'denounce the publican and pass the drunkard by.' 12 The 1902 Licensing Act had, of course, ramped up the restrictive nature of alcohol sale and control. Most importantly, the act put the onus on publicans and retailers to control the sale of drink and stem drunkenness within their establishments. It was felt that this singled out publicans as the purveyors of social evils

Outside of fanaticism, every-one knows that licenses in the hands of respectable men, who respect the law and are respected by it, are legitimate and necessary, and their holding a respectable and necessary vocation. ${ }^{13}$

The counter-argument to the teetotal view was that the sale of drink was a legitimate and necessary vocation and a respectable one at that. The trade journals were therefore driven to promote and advertise the positive side of the liquor trade. An article in The Scottish Wine, Beer and Spirits Trades Review in 1895 reported on the annual festival of the Glasgow Wine, Beer and Spirits Trades Employees Benevolent Association. The main speech, given by Mr George MacLauchlan, the Vice President of the Association, focused on the 'slander of temperance extremists'

A Trade the capital embarked in which exceeds 2 million Sterling; a Trade contributing to the revenue of the country to an extent of 40 million; a Trade funding employment for about 2 million of our population cannot be ignored and which commands imperative public recognition. What other trade in Glasgow contributes to any such extent? None ... It is with sobriety, education and intelligence that out Trade prospers and can only prosper. The curse of our Trade is the drunkard, the friend - the sober (applause). I admit there are men so constituted that they cannot, without serious consequences, taste alcohol at all. These are the small and numerically trifling exception, although it is the example furnished by them that is seized upon by our opponents as warranting an attack upon our Trade thereby falsifying alike logic and reason. ${ }^{14}$

MacLauchlan gave a rousing speech which delivered a strong argument and raised some key questions: if the local and national economy 
benefitted from the sale of alcohol, why the lack of gratitude? And if the majority of consumers drank in a moderate and respectable fashion, why attribute drunkenness to the liquor trade? Surely that was evidence enough that the trade served the public in a responsible way. Yet the one damning thing that made all that irrelevant was the very thing that kept the liquor trade afloat: alcohol. There simply was no way to guarantee that an intoxicant that came in so many varieties and strengths could always be consumed in a moderate and respectable fashion-the spectre of the drunkard was proof of that.

It was also difficult for 'respectable' members of the liquor trade to avoid the shadow cast by the disreputable side of the business. Therefore, many articles in the trade journals, particularly after 1900, dealt with the issues of unlicensed shebeens and bogus drinking clubs. One article in The Victualing Trades Review in 1904 offered an expose on a bogus club in Glasgow's East End. It claimed that there were around 200 bogus drinking clubs operating in Glasgow and that most sold cheap 'raw' whisky and poor quality beer. The clubs opened after the pubs closed on Saturdays and Sundays and remained open until the small hours of the morning. The article reported on a club known as The Literary and Social Institution in which it claimed there was:

... no literature, and the social intercourse of the members lay principally in discussions as to what would win the 'back-end' handicap at Newmarket, forthcoming prize fights and the like. If heavy drinking counts as social intercourse, then the club really fulfilled to the hilt one of its missions for I have seen more liquor put away here in a couple of hours than would be sold over the bar in a small public house in a day. ${ }^{15}$

As a consequence of increasingly restrictive licensing and forced reductions in pub numbers, the trade knew that in order to survive, it had to be seen to operate in a respectable manner. It was therefore important to differentiate and distance themselves from disreputable vendors and drunken customers. Another article in The National Guardian in 1908 explored the issue of publicans and intemperance

The publican alone, among merchants, habitually refuses undesirable business and he necessarily regards his drunken customer with aversion. $\mathrm{He}$ does not wish such to enter his shop ... respectable people will not frequent a bar patronized by the vicious and disorderly and in order to keep 
his respectable customers pleased and content, the proprietor discourages traffic with obnoxious characters. ${ }^{16}$

A well-run establishment serving respectable, moderate-drinking customers was the trade ideal and this was precisely the image that publicans and licensed victuallers endeavoured to cultivate and promote both publicly and within their own ranks. Still, there was no escaping the 'threat' of drunkenness posed by the substance they dealt in. So, it was also important that alcohol itself was regarded not as a dangerous intoxicant but rather as a benign social lubricant. The trade journals carried many articles that promoted the social side of drinking by reporting on different pubs, drinking occasions and drinking customs in different countries. A piece in The Victualing Trades Review from 1900 listed the 'drinks of great men' and included Otto von Bismarck the German Chancellor who, as a 'staunch patriot' was known to drink mainly German beer and German wine. Gladstone drank claret and port and used a mix of sherry and egg yolk as a 'vocal lubricant' before public speaking, and Balfour preferred port. ${ }^{17}$ The light-hearted tone of the piece did not disguise its intent to promote alcohol consumption as an intrinsic attribute found among 'great men'. There were few teetotallers listed and much use was made of the term 'moderate drinking'.

A constant theme throughout the years leading up to 1914 was the issue of why people consumed alcohol at all and it was vital that the trade devised reasons for drinking other than getting drunk. This was particularly the case in Scotland with the passing of The Temperance (Scotland) Act in 1913, which gave local voters the right to withhold licenses to sell alcohol in their districts. The looming threat of local veto meant that there had to be good reasons for drinking alcohol. An article in The National Guardian in 1913 written by 'a medical man' explored the psychological effects of alcohol

What the vast majority of persons who drink alcohol drink do it for is not because they like the taste of it, nor because they are thirsty, but for what is sometimes called its physiological effect, but what ought to be called its psychological effect-that is to say, in plain terms, because it makes them feel jolly. It raises their spirits. It confers happiness. It gives them a good conceit of themselves. Is it any wonder that it is so much valued by the English, who are so wanting in this useful sentiment? ... if it is taken regularly and always with the same moderation, although the full euphoric 
effect is not produced, some effect is produced; and the regular imbiber of moderate doses of alcohol is so much better off than the abstainer that though he does not attain the hilarious exhilaration of his first dose, he yet reaches a placid contentment, a good natured geniality. ${ }^{18}$

It was important for the trade to identify and promote the positive aspects of alcohol consumption. These could be social uses in dining and conviviality or drinking healths and toasts. Or as this quote demonstrates, alcohol could have the psychological effect of 'lifting the spirits' or making people 'feel jolly.' However, the key to securing the continued fortunes of the trade in alcohol lay in the direction of moderate drinking. This was known to the trade and also to alcohol consumers, as demonstrated by the formation of The National Temperate Society in Manchester in 1907. The society was formed to 'combat the uncalled for interference with the liberties of citizens who choose to indulge to a moderate extent in alcoholic liquors.' 19 The Manchester Courier reported on the activities of the society, which by 1907 had 700 members who embarked on 'missionary work' in local pubs to try and induce customers to form branches

That class of the community known as 'moderate drinkers', men who after a day's work enjoy an hour or two's social intercourse on licensed premises, have discovered that their rights were being menaced, and in one part of Manchester have banded themselves together under the title of The National Temperate Society with the object of resisting any unreasonable interference with the liberty of pleasing themselves. ${ }^{20}$

In the shadow cast by the spectre of the drunkard, drink became a political issue and by the turn of the century, the principles of laissez faire no longer supported an industry that dealt in intoxication. Increased state control over alcohol sale and consumption impacted not only upon the livelihoods and reputation of the drink trade but also on alcohol consumers and as the quote above demonstrates, some were prepared to campaign for the freedom to drink. The members of the National Temperate Society argued that not all paths led to Rome-in other words, not every drinker was a drunkard. There were many reasons why people across Britain consumed alcohol and many different types of drinking behaviour, other than drunkenness. 


\section{Notes}

1. House of Commons Parliamentary Papers (HCPP). 1899: c. 9076: Royal Commission on Liquor Licensing Laws: Volume XI: Précis of Minutes of Evidence: Appendix 5: Summary reports from Royal, Select and Departmental Committees on the liquor traffic in Great Britain and Ireland.

2. Fahey D. 1971. 'Temperance and the Liberal Party-Lord Peel's Report, 1899': Journal of British Studies: Volume 10:2: p. 135.

3. HCPP. 1899: c. 9076: Royal Commission on Liquor Licensing Laws: Volume XI: Précis of Minutes of Evidence: Appendix 5.

4. HCPP. 1899: c. 9076: Royal Commission on Liquor Licensing Laws: Volume XI: Précis of Minutes of Evidence: Appendix 5.

5. HCPP. 1899: c. 9076: Royal Commission on Liquor Licensing Laws: Volume XI: Précis of Minutes of Evidence: Appendix 5.

6. HCPP. 1899: c. 9076: Royal Commission on Liquor Licensing Laws: Volume XI: Précis of Minutes of Evidence: Appendix 5.

7. Harrison B. 1971. Drink and the Victorians: The Temperance Question in England 1815-1872: London: Faber \& Faber: p. 12.

8. Nicholls J. 2011. The Politics of Alcohol: A History of the Drink Question in England: Manchester: Manchester University Press: pp. 130-131.

9. HCCP. 1897. The Departmental Commission on Habitual Offenders (Scotland): p. vi.

10. HCCP. 1897. The Departmental Commission on Habitual Offenders (Scotland): Testimony of Father John McMillan: p. 74.

11. 'Why Do People Take Alcohol?' The National Guardian: January 1913.

12. 'Why Do People Take Alcohol?' The National Guardian: January 1913.

13. 'Why Do People Take Alcohol?' The National Guardian: January 1913.

14. 'Wine, Spirits and Beer Trades Employees Festival': The Scottish Wine, Spirit and Beer Trades Review: 1895.

15. 'Sunday in a Drinking Club: The Unlicensed Pub': The Victualing Trades Review: 1904.

16. 'Publicans and Intemperance': The National Guardian: April 1908.

17. 'The Drinks of Great Men': The Victualing Trades Review: 1900.

18. 'Drunkenness and the Physiological Effect of Alcohol': The National Guardian: January 1913.

19. 'Moderate Drinkers: To Combat Teetotal Intolerance': The Manchester Courier and Lancashire General Advertiser: 11 April 1907.

20. 'Moderate Drinkers: To Combat Teetotal Intolerance': The Manchester Courier and Lancashire General Advertiser: 11 April 1907. 
24 T. HANDS

Open Access This chapter is licensed under the terms of the Creative Commons Attribution 4.0 International License (http://creativecommons.org/licenses/ by $/ 4.0 /$ ), which permits use, sharing, adaptation, distribution and reproduction in any medium or format, as long as you give appropriate credit to the original author(s) and the source, provide a link to the Creative Commons license and indicate if changes were made.

The images or other third party material in this chapter are included in the chapter's Creative Commons license, unless indicated otherwise in a credit line to the material. If material is not included in the chapter's Creative Commons license and your intended use is not permitted by statutory regulation or exceeds the permitted use, you will need to obtain permission directly from the copyright holder.

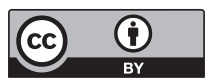

